\title{
Pheochromocytoma of the urinary bladder: a systematic review of the contemporary literature
}

\author{
Jonathan A Beilan ${ }^{1,2}$, Adrienne Lawton ${ }^{3}$, Julio Hajdenberg ${ }^{4}$ and Charles J Rosser ${ }^{1,2^{*}}$
}

\begin{abstract}
Background: Pheochromocytoma (paraganglioma) of the urinary bladder is a rare tumor. Herein we sought to review the contemporary literature on pheochromocytomas of the urinary bladder in order to further illustrate the presentation, treatment options and outcomes of patients diagnosed with these tumors.

Methods: A comprehensive review of the current literature was conducted according to the PRISMA guidelines by accessing the NCBI PubMed database and using the search terms "paraganglioma, pheochromocytoma, bladder." This search resulted in the identification of 186 articles published between January 1980 and April 2012 of which 80 articles were ultimately included in our analysis.

Results: Pheochromocytomas usually occurred in young adult Caucasians (mean age, 43.3 years; range, 11-84 years). According to the literature, the most common symptoms and signs of pheochromocytomas of the urinary bladder were hypertension, headache, and hematuria. Of the 77 cases that commented on catecholamine production, 65 patients had biochemically functional tumors. Approximately $20 \%$ of patients were treated by transurethral resection alone, $70 \%$ by partial cystectomy and $10 \%$ by radical cystectomy. The 75 patients with follow-up information had a mean follow-up of 35 months. At the time of last follow-up, 15 (14.2\%) had disease recurrence, 10 (9.4\%) had metastasis, and 65 (61.3\%) were alive.

Conclusions: Pheochromocytomas of the urinary bladder tend to be functional and occur mostly in young adult Caucasians. Patients with localized tumors have an extremely favorable prognosis and may be managed by less aggressive modalities, whereas patients with metastatic disease have a significant reduction in survival rates despite aggressive treatment.
\end{abstract}

Keywords: Paraganglioma, Pheochromocytoma, Bladder, Treatment, Diagnosis, Prognosis

\section{Background}

Pheochromocytoma of the urinary bladder is a rare tumor that originates from chromaffin tissue of the sympathetic nervous system associated with the urinary bladder wall. Pheochromocytomas are tumors of the sympathetic nervous tissue and may be non-functional or functional, i.e., secrete catecholamine causing paroxysmal hypertension, palpitation, and micturition syncope [1]. Typically these tumors possess the capacity to invade and thus are deemed malignant, yet lack mitoses and cellular dissociation that are usually associated with malignant tumors [2]. Numerous, small series case reports have been

\footnotetext{
* Correspondence: charles.rosser@orlandohealth.com

'Section of Urologic Oncology, MD Anderson Cancer Center Orlando, $1400 \mathrm{~S}$. Orange Ave, Orlando, FL 32806, USA

${ }^{2}$ College of Medicine, University of Central Florida, Orlando, FL 32827, USA

Full list of author information is available at the end of the article
}

published in the English literature since it was first reported in 1953 by Zimmerman et al. [3]. Herein we sought to review the contemporary literature on pheochromocytoma of the urinary bladder in hopes of further clarifying presentation, treatment options and outcomes of patients with pheochromocytomas of the urinary bladder.

\section{Methods}

A review of the current literate was conducted by accessing the NCBI PubMed database (http://www.ncbi. nlm.nih.gov/pubmed). Filters applied in an advanced search included: the search terms of "paraganglioma, pheochromocytoma, bladder"; English language; human subjects 19 years of age and older; publication dates of January 1980 to April 2012. Figure 1 illustrates the work-flow of the comprehensive literature review, which

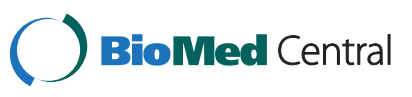




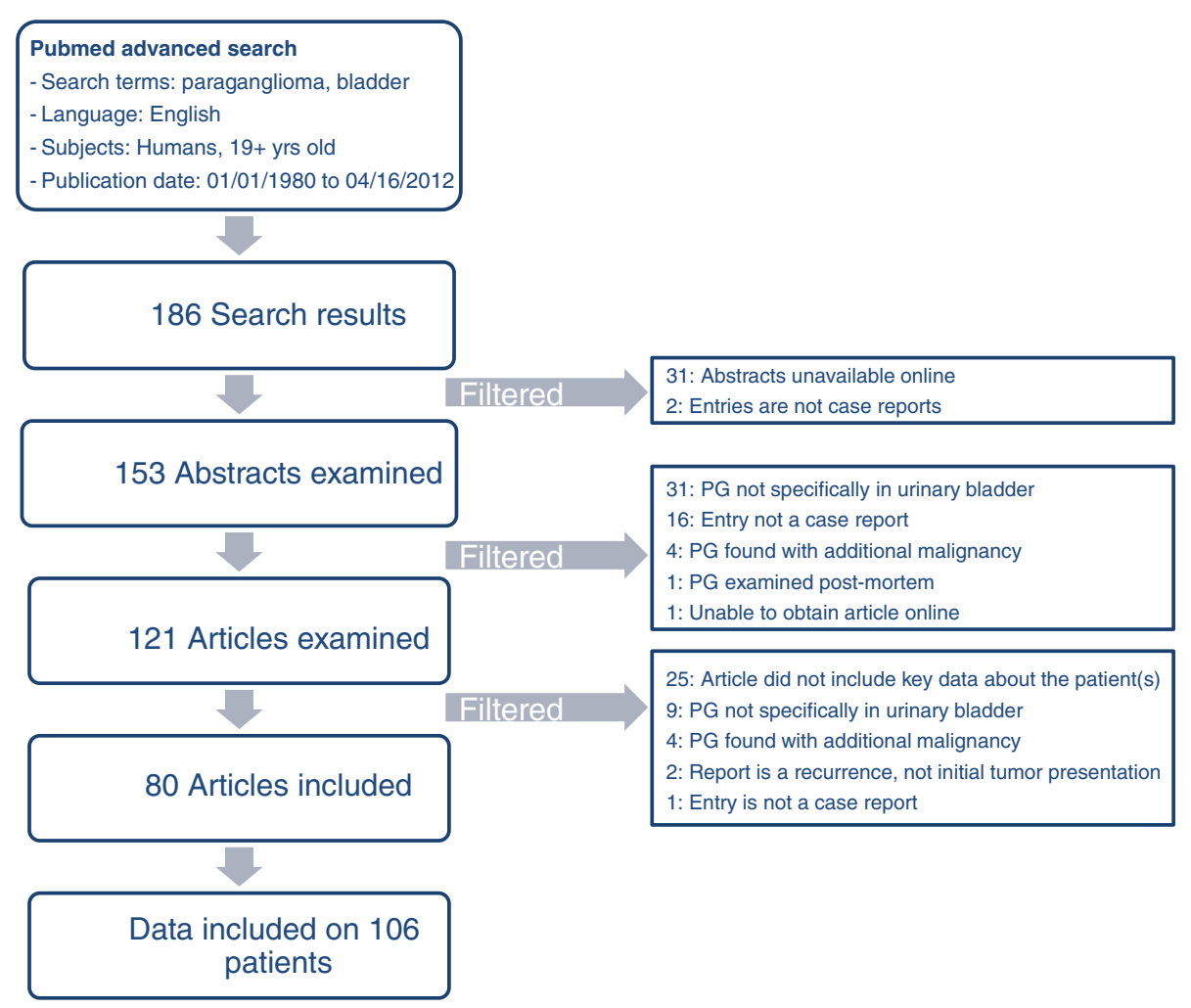

Figure 1 Literature search schema.

adhered to the PRISMA systematic review guidelines [4]. This search delivered 186 results from which 153 abstracts were reviewed. A total of 121 articles were ultimately reviewed in full. Patient characteristics were divided into "primary" and "secondary" demographics for ease of data recording. Reasons for exclusion included missing any primary demographic (patient age, sex, presenting symptoms, type of surgery) or more than three secondary demographics (patient race, catecholamine levels, tumor size, tumor grade and stage, last follow up). Due to failure to report primary demographics and/or secondary demographics, an additional 25 articles eventually were excluded from final analysis. Thus the final analysis comprised 80 articles that reported on 106 patients. Relevant clinical, pathologic, laboratory, radiologic and follow-up data from these 80 articles were collected in a database, which allowed the reporting of descriptive statistics.

\section{Results}

Eighty articles on pheochromocytoma of the urinary bladder were identified on Pubmed and were incorporated in our analysis, which included 106 patients [4-82]. The demographics and presenting symptomology are summarized in Table 1 . The mean patient age was 43.3 years (range, $11-84$ years). The male-to-female ratio was 1.07 to 1 . The most common symptoms were hypertension (54.7\%), headache (48.1\%), hematuria (47.2\%) and syncope/palpitations (43.4\%). Micturition attacks were reported in $52.8 \%$ of patients.

Average tumor size was $3.9 \mathrm{~cm}$ (median 3.45, range $1-9.1 \mathrm{~cm})$. Few studies $(\mathrm{n}=7)$ reported exact tumor stage by the TNM criteria. Of the 106 patients, 65 (61.3\%) were noted to have a functional paraganglioma as evident by elevated VMA, metanephrine and/or catecholamines. Furthermore, limited articles reported on CD56, Chromagranin A, and synaptophysin immunohistochemical staining.

The most commonly reported treatment for patients with paraganglioma of the urinary bladder was partial cystectomy 73 (68.9\%). Other treatment options for localized/locally advanced paraganglioma of the urinary bladder include TURBT $(21 ; 19.8 \%)$ and radical cystectomy $(12 ; 11.3 \%)$. Thirty-one patients included in this study did not have known follow-up. Mean follow of the remaining cohort was 34.6 months (median 18; range $0.75-372$ months). Fifteen patients (14.2\%) were noted to develop a recurrence of the tumor, while 60 patients $(56.6 \%)$ had no evidence of disease. Metastatic recurrence was noted in ten patients (9.4\%). Ten patients (9.4\%) were deceased at last follow-up. Of these 10 patients who died, four (3.8\%) presented with locally advanced or metastatic disease. Thus, patients who presented 
Table 1 Demographics and presenting symptoms

\begin{tabular}{ll}
\hline Variable & N (\%) \\
\hline Total Patients & 106 \\
Sex & \\
Males & 55 \\
Female & 51 \\
Age & \\
Mean age (years) & 43.3 \\
Age range (years) & $11-84$ \\
Presenting symptom(s) & \\
Micturition attacks & $56(52.8)$ \\
Hypertension & $58(54.7)$ \\
Headache & $51(48.1)$ \\
Hematuria & $50(47.2)$ \\
Syncope/palpitations & $46(43.4)$ \\
Diaphoresis & $21(19.8)$ \\
Micturition disturbances (e.g., urgency, dysuria) & $11(10.4)$ \\
Dizziness & $10(9.4)$ \\
Abdominal/flank pain & $6(5.7)$ \\
Dyspnea/chest pain & $5(4.7)$ \\
Malaise & $3(2.8)$ \\
Incidental finding & $3(2.8)$ \\
Other & $11(10.4)$ \\
Catecholamines & \\
UMnA, metanephrine, or catecholamines & $65(61.3)$ \\
Unknown/not mentioned & $29(27.4)$ \\
Median (range) (cm) & $3.95(1.0-9.1)$ \\
\hline & \\
Unknown/not mentioned & \\
\hline
\end{tabular}

with localized paraganglioma of the urinary bladder have a significantly improved survival compared to patients who presented with locally advanced/metastatic disease.

\section{Discussion}

Pheochromocytomas of the urinary bladder are exceedingly rare tumors accounting for less than $0.05 \%$ of all bladder tumors and less than $1 \%$ of all pheochromocytomas. In the genitourinary tract, the urinary bladder is the most common site for pheochromocytomas (79.2\%), followed by the urethra $(12.7 \%)$, pelvis $(4.9 \%)$, and ureter $(3.2 \%)$ $[82,83]$. Furthermore, approximately $10 \%$ of all extra adrenal pheochromocytomas are malignant [83]. Since this is such a rare condition, limited, large reports are available to direct clinical decision making. We extensively reviewed the English literature on this subject and report the largest analysis of pheochromocytomas involving the urinary bladder. Our study improves upon previous large reviews [5,84]. For example, Tsai et al. includes one study dating back to 1911, and then eleven studies between 1989 and 2000 [5]. Our study includes 80 studies between 1980 and 2012, offering a better view for analyzing contemporary outcomes. In addition, we have a total of 106 patients included in our study, the most of any literature review to date, while Tsai et al. only reported on 53 patients. Lastly, our review used a multitude of demographics to depict the disease process of bladder pheochromocytomas, including presenting symptoms, tumor functionality, tumor size, treatment modality and outcomes.

Symptoms reported in the current literature range from the typical micturition attacks of headache and palpitations to more abstract signs such as paraesthesias and dyspnea. While select patients may lack more common presenting symptoms of bladder pheochromocytoma, e.g., hypertension, others may develop hematuria and lower urinary tract symptoms, testifying to the variability in which this disease can present itself. Furthermore, the consequences of hypertension itself may muddle the initial diagnostic picture of these patients. Patients often seek medical attention only when their hypertension has become so advanced as to cause syncope, retinopathy, or intracranial hemorrhage [85]. Physicians must constantly be wary of an undiagnosed pheochromocytoma in the setting of unexplained hypertension or associated symptoms.

Pheochromocytomas can be treated in a number of ways, including catecholamine blockade, surgery, chemotherapy, and radiation therapy. The standard treatment modality for localized or locally advanced pheochromocytomas is surgery, while metastatic or recurrent tumora are treated with palliative therapy [86]. Furthermore, physicians must be aware of poor prognostic indicators, such as large tumor size, advanced stage ( $\geq \mathrm{T} 3)$, multifocal tumors, DNA ploidy, and CgA expression [84]. The cyclophosphamide, vincristine, and dacarbazine (the Averbuch protocol) has been shown to be effective against advanced malignant pheochromocytoma [87]. Radiation therapy with ${ }^{131}$ I-MIBG radiation therapy has been used with good efficacy for the treatment of MIBG-avid metastases [88]. Approximately $70 \%$ of patients included in our literature review underwent partial cystectomy as a means of primary treatment. Including those who underwent radical cystectomy, over $80 \%$ of patients were initially treated with aggressive surgical excision. Of the $75 \mathrm{pa}-$ tients with reported follow up, 15 (20\%) experienced recurrence or metastasis at the time of last follow-up, illustrating that good symptomatic control and lower morbidity can be achieved with the surgical resection. It is important to note, however, that 4 of these 75 patients (5.3\%) did have recurrence or metastases that ultimately caused their death. In the face of metastatic pheochromocytoma, surgical treatment is rarely curative. It may, however, 
adequately prolong survival by reducing comorbid conditions (i.e. hypertension) and reducing tumor burden, but adjunct therapies are usually indicated [89]. Thus patients should be counseled according to their individual presentation and disease status.

Furthermore, with a lack of high quality data and the lack of organizational guidelines (e.g., EAU, NCCN and AUA) on post-operative follow-up, we recommend no follow-up studies in patients with benign, localized disease. In patients with functional tumors, regardless of stage, VMA, metanephrine and catecholamines levels should be monitored within one month post-surgery, then every six months for two years. Furthermore if regional or metastatic is documented then axial imaging of the abdomen/pelvis should be performed every three months for one year, then every six months for one year, then yearly for three years.

The main limitations of our study relate to its retrospective nature and the large disparity among reporting styles of various institutions. For example, the vast majority of case reports included in this study report on patients presenting with localized or regional disease rather than metastatic disease. This may represent a bias toward reporting on patient's who's therapeutic timeline can better be used as an educational platform. The lack of uniformity on how oncologic cases are presented makes it difficult to characterize the true disease course of bladder pheochromocytoma. Information such as patient race, diagnostic findings, and laboratory values should be included whenever possible to better illustrate the pathophysiologic process. Currently, there is no standard staging system for pheochromocytomas. The National Cancer Institute at the National Institute of Health recommends dividing patients into three categories: localized, regional, and metastatic disease. In terms of grade and cellular classification of these tumors, the NCI identifies four pathologic features associated with malignancy: large tumor size, increased number of mitosis, DNA aneuploidy, and extensive tumor necrosis [86]. The complete tumor stage and grade are vital additions to any oncologic case report. Describing these characteristics and developing standard reporting criteria will enable future investigations to better collect and analyze information from case reports.

\section{Conclusions}

In summary, pheochromocytomas of the urinary bladder tend to be functional and occur mostly in young adult Caucasians. Initial presentation is extremely varied in these cancers, necessitating a low threshold of suspicion in the face of hypertension or hematuria. Patients with localized tumors have a favorable prognosis and may be managed by less radical modalities, whereas patients with metastatic disease have a significantly reduced survival rate. Moving forward, it would be helpful to standardize the reporting guidelines of pheochromocytomas cases to better understand the natural process and outcomes.

\section{Abbreviations}

AUA: American Urological Association; VMA: vanillylmandelic acid; H\&E: Hematoxylin and eosin; IHC: Immunohistochemical.

\section{Competing interests}

The authors declare that they have no competing interests.

\section{Authors' contributions}

$J A B, B S$ : Acquisition of data, statistical analysis and drafting manuscript. AL, MD: Pathologic interpretation of case report and acquisition pathologic images. JH, MD: Analysis of data and drafting of manuscript. CJR, MD, MBA: Study concept and design, drafting of manuscript. All authors have read and approved the final manuscript.

\section{Funding}

Articles not available to the general public were retrieved through the University of Central Florida College of Medicine Library system and the UCF COM interlibrary loan system ILLiad. No other funding or outside resources were used for the completion of this study.

\section{Author details}

${ }^{1}$ Section of Urologic Oncology, MD Anderson Cancer Center Orlando, $1400 \mathrm{~S}$ Orange Ave, Orlando, FL 32806, USA. ${ }^{2}$ College of Medicine, University of Central Florida, Orlando, FL 32827, USA. ${ }^{3}$ Department of Pathology, Orlando Health/MD Anderson Cancer Center Orlando, Orlando, FL 32806, USA.

${ }^{4}$ Section of Genitourinary Oncology, MD Anderson Cancer Center Orlando, Orlando, FL 32806, USA.

Received: 13 November 2012 Accepted: 25 April 2013 Published: 29 April 2013

\section{References}

1. Sheps SG, Jiang NS, Klee GG, et al: Recent developments in the diagnosis and treatment of pheochromocytoma. Mayo Clin Proc 1990, 65:88-95.

2. Zhou M, Epstein Jl, Young RH: Paraganglioma of the urinary bladder: a lesion that may be misdiagnosed as urothelial carcinoma in transurethral resection specimens. Am J Surg Pathol 2004, 28:94-100.

3. Zimmerman IJ, Biron RE, Macmahon HE: Pheochromocytoma of the urinary bladder. N Engl J Med 1953, 249:25-26.

4. Moher D, Liberati A, Tetzlaff J, Altman DG, PRISMA Group: Preferred reporting items for systematic reviews and meta-analyses: the PRISMA statement. PLoS Med 2009, 6(7):e1000097.

5. Tsai CC, Wu WJ, Chueh KS, Li WM, Huang CH, Wu CC, Lee MH, Chen SM: Paraganglioma of the urinary bladder first presented by bladder bloody tamponade: two case reports and review of the literatures. Kaohsiung J Med Sci 2011, 27(3):108-113.

6. Nayyar R, Singh P, Gupta NP: Robotic management of pheochromocytoma of the vesicoureteric junction. JSLS: Journal of the Society of Laparoendoscopic Surgeons/Society of Laparoendoscopic Surgeons 2010, 14:309-312.

7. Pandey R, Garg R, Roy K, Darlong V, Punj J, Kumar A: Perianesthetic management of the first robotic partial cystectomy in bladder pheochromocytoma. A case report. Minerva Anestesiol 2010, 76:294-297.

8. Oderda M, Michelon F, Appendino M, et al: Primary bladder phaeochromocytoma diagnosed by a Vet. Scand J Urol Nephrol 2010, 44:186-189.

9. Vesin C, Cadi P, Thony F, et al: A rare cause of complicated hypertension: urinary bladder paraganglioma. South Med J 2009, 102:1173-1175.

10. Huang Y, Tian XJ, Ma LL: Pre-peritoneal laparoscopic partial cystectomy of the bladder pheochromocytoma. Chin Med J 2009, 122:1234-1237.

11. Dhawan DR, Ganpule A, Muthu V, Desai MR: Laparoscopic management of calcified paraganglioma of bladder. Urol J 2008, 5:126-128.

12. Im SH, Kim NH: Thunderclap headache after micturition in bladder pheochromocytoma. Headache 2008, 48:965-967. 
13. Siatelis A, Konstantinidis C, Volanis D, Leontara V, Thoma-Tsagli E, Delakas D: Pheochromocytoma of the urinary bladder: report of 2 cases and review of literature. Italian J Urol Nephrol 2008, 60:137-140.

14. Kappers $\mathrm{MH}$, van den Meiracker AH, Alwani RA, Kats E, Baggen MG: Paraganglioma of the urinary bladder. Neth J Med 2008, 66:163-165.

15. Zwahlen D, Fishman PN, Honey J, Milosevic M, Tannock I: Malignant pheochromocytoma of the urinary bladder. Can J Urol 2007, 14:3455-3457.

16. Bhalani SM, Casalino DD, Manvar AM: Paraganglioma of the bladder. J Urol 2011, 186:279-280

17. Kang SG, Kang SH, Choi H, Ko YH, Park HS, Cheon J: Robot-assisted partial cystectomy of a bladder pheochromocytoma. Urol Int 2011, 87:241-244.

18. Havekes B, Corssmit EP, Jansen JC, van der Mey AG, Vriends AH, Romijn JA: Malignant paragangliomas associated with mutations in the succinate dehydrogenase D gene. J Clin Endocrinol Metabol 2007, 92:1245-1248.

19. Tsutsui A, Omoto K, Eto M, Naito S: Unsuspected pheochromocytoma of the urinary bladder in an 81-year-old woman. Hinyokika Kiyo Acta Urologica Japonica 2006, 52:577-579.

20. Bozbora A, Barbaros U, Erbil Y, Kilicarslan I, Yildizhan E, Ozarmagan S: Laparoscopic treatment of hypertension after micturition: Bladder pheochromocytoma. J Soc Laparoendoscopic Surgeons/Society of Laparoendoscopic Surgeons 2006, 10:263-266.

21. Dilbaz B, Bayoglu Y, Oral S, Cavusoglu D, Uluoglu O, Dilbaz S: Laparoscopic resection of urinary bladder paraganglioma: a case report. Surg LaparosC Endosc Percutan Tech 2006, 16:58-61.

22. Segawa N, Osafune T: Malignant pheochromocytoma of the urinary bladder. Hinyokika Kiyo Acta Urologica Japonica 2005, 51:291-296.

23. Minagawa T, Sato T, Furuhata M, Hirabayashi N, Kato H: Extra-adrenal pheochromocytoma (paraganglioma) of the urinary bladder: a case report. Hinyokika Kiyo Acta Urologica Japonica 2004, 50:787-790.

24. Pastor-Guzman JM, Lopez-Garcia S, Gimenez-Bachs JM, et al: Paraganglioma of the bladder: controversy regarding treatment. Urol Int 2004, 73:270-275.

25. Jacob S, Prabhakar BR, Kakkar N, Mammen K: Paraganglioma of the urinary bladder-a case report. Indian J Pathol Microbiol 2003, 46:652-653.

26. Yoshida S, Nakagomi K, Goto S, Kobayashi S: Malignant pheochromocytoma of the urinary bladder: effectiveness of radiotherapy in conjunction with chemotherapy. Int J Urol 2004, 11:175-177.

27. Gasic S, Heinz-Peer G, Kurtaran A, Pirich C, Kratzik C, Koller A: Paroxysmal hypertension during micturition. Am J Hypertens 2004, 17:100-101

28. Onishi T, Sakata Y, Yonemura S, Sugimura Y: Pheochromocytoma of the urinary bladder without typical symptoms. Int J Urol 2003, 10:398-400.

29. Kang WY, Shen JT, Chai CY: Paraganglioma of the urinary bladder: a case report. Kaohsiung J Med Sci 2003, 19:136-140.

30. Doran F, Varinli S, Bayazit Y, Bal N, Ozdemir S: Pheochromocytoma of the urinary bladder. Acta Pathol Microbiol Immunol Scand 2002, 110:733-736.

31. Tan SM, Chan ST: An undiagnosed phaeochromocytoma of the urinary bladder. Anaesth Intensive Care 2002, 30:668-670.

32. Lamarre-Cliche M, Hernigou A, Boutouyrie P, Plouin PF, Azizi M: Images in cardiovascular medicine. Pheochromocytoma of the urinary bladder. Circulation 2002, 106:2143-2144.

33. Ali-el-Dein B: el-Sobky E, el-Baz M, Shaaban AA. Abdominal and pelvic extra-adrenal paraganglioma: a review of literature and a report on 7 cases. In Vivo 2002, 16:249-254.

34. Dewan M, Rasshid M, Elmalik EM, Ansari MA, Morad N: Lessons to be learned: a case study approach. Paraganglioma of the urinary bladder. J R Soc Promot Health 2001, 121:193-198.

35. Moritani H, Sakamoto M, Yoshida Y, Nasu H, Nemoto R, Nakamura I: Pheochromocytoma of the urinary bladder revealed with cerebral hemorrhage. Intern Med 2001, 40:638-642.

36. Kozlowski PM, Mihm F, Winfield HN: Laparoscopic management of bladder pheochromocytoma. Urology 2001, 57:365.

37. Seki N, Mukai S, Gamachi A, Migita T, Maeda K, Ogata N: A case of bladder pheochromocytoma. Urol Int 2001, 66:57-60.

38. Baima C, Casetta G, Vella R, Tizzani A: Bladder pheochromocytoma: a 3-year follow-up after transurethral resection (TURB). Urol Int 2000, 65:176-178.

39. Gyftopoulos K, Perimenis P, Ravazoula P, Athanassopoulos A, Barbalias GA: Pheochromocytoma of the urinary bladder presenting only with macroscopic hematuria. Urol Int 2000, 65:173-175.

40. Rajaratnam S, Seshadri MS, Gopalakrishnan G, Chandi SM: Phaeochromocytoma of the urinary bladder. J Assoc Physicians India 1999, 47(2):246-247.
41. Singh DV, Seth A, Gupta NP, Kumar M: Calcified nonfunctional paraganglioma of the urinary bladder mistaken as bladder calculus: a diagnostic pitfall. BJU Int 2000, 85:1152-1153.

42. Panichi S, Dell'Anna G, Innocenti P, Nesi G: Paraganglioma of the bladder report of a case. Annali Italiani Di Chirurgia 1999, 70:937-939.

43. Sanjoaquín MT, Fraile JR, Gutiérrez A, Canal MI, Navia J: Hypertensive crisis during a transurethral resection of the bladder: nondiagnosed bladder paraganglioma. Anesth Analg 2000, 90(3):556-558.

44. Kato H, Suzuki M, Mukai M, Aizawa S: Clinicopathological study of pheochromocytoma of the urinary bladder: immunohistochemical, flow cytometric and ultrastructural findings with review of the literature. Pathol Int 1999, 49:1093-1099.

45. Shono T, Sakai H, Minami Y, Suzu H, Kanetake H, Saito Y: Paraganglioma of the urinary bladder: a case report and review of the Japanese literature. Urol Int 1999, 62:102-105.

46. Fujishima $\mathrm{S}, \mathrm{Abe}$ I, Kaseda $\mathrm{S}$, et al: Ambulatory blood pressure monitoring in diagnosing a pheochromocytoma of the urinary bladder. A case report. Angiology 1997, 48:655-658.

47. Piedrola G, Lopez E, Rueda MD, Lopez R, Serrano J, Sancho M: Malignant pheochromocytoma of the bladder: current controversies. Eur Urol 1997, 31:122-125.

48. Asbury WL Jr, Hatcher PA, Gould HR, Reeves WA, Wilson DD: Bladder pheochromocytoma with ring calcification. Abdom Imaging 1996, 21:275-277.

49. Lee SP, Wang GG, Hwang SC, Chen MT, Lin HD: Pheochromocytoma of the urinary bladder: a case report. Chin Med J 1996, 57:297-300.

50. Nesi G, Vezzosi V, Amorosi A, Menghetti I, Selli C: Paraganglioma of the urinary bladder. Urol Int 1996, 56:250-253.

51. Kyriakidis A, Dimitriou D, Stiakakis I: A clinical diagnosis of urinary bladder (extra-adrenal) phaeochromocytoma. Acta Urol Belg 1995, 63:65-66.

52. Takimoto E, Ueda W: Unsuspected pheochromocytoma of the urinary bladder. Anesth Analg 1995, 80:1243-1244.

53. Nargund VH, Gouldesbrough DR, Stewart PA: A self-made diagnosis of phaeochromocytoma of the urinary bladder. Br J Urol 1994, 73:220-222.

54. Thrasher JB, Rajan RR, Perez LM, Humphrey PA, Anderson EE: Pheochromocytoma of urinary bladder: contemporary methods of diagnosis and treatment options. Urology 1993, 41:435-439.

55. Suzuki Y, Nakada T, Suzuki H, et al: Primary bladder pheochromocytoma without hypertension. Int Urol Nephrol 1993, 25:153-158.

56. Misawa T, Shibasaki T, Toshima R, et al: A case of pheochromocytoma of the urinary bladder in a long-term hemodialysis patient. Nephron 1993, 64:443-446.

57. Jurincic C, Gasser A, Metz KA, Kjelstrup T, Klippel KF: Pheochromocytoma of the urinary bladder. Urol Int 1992, 48:232-234

58. Hansen LU, Jess P, Hermansen K, Lorentzen M: Phaeochromocytoma-an unusual cause of haematuria. Scand J Urol Nephrol 1992, 26:319-321.

59. Grignon DJ, Ro JY, Mackay B, et al: Paraganglioma of the urinary bladder: immunohistochemical, ultrastructural, and DNA flow cytometric studies. Hum Pathol 1991, 22:1162-1169.

60. Frydenberg M, Ferguson R, Langdon P, Rogers J, McCarthy S: Malignant phaeochromocytoma of the bladder-active or inactive. Br J Urol 1991 67:548-549.

61. Sweetser PM, Ohl DA, Thompson NW: Pheochromocytoma of the urinary bladder. Surgery 1991, 109:677-681.

62. Warshawsky R, Bow SN, Waldbaum RS, Cintron J: Bladder pheochromocytoma with MR correlation. J Comput Assist Tomogr 1989, 13:714-716.

63. Punekar S, Gulanikar A, Sobti MK, Sane SY, Pardanani DS: Pheochromocytoma of the urinary bladder-report of 2 cases with review of literature. J Postgrad Med 1989, 35:90-92.

64. Splinter WM, Milne B, Nickel C, Loomis C: Perioperative management for resection of a malignant non-chromaffin paraganglioma of the bladder. Can J Anaesth 1989, 36:215-218.

65. Salo JO, Miettinen M, Makinen J, Lehtonen T: Pheochromocytoma of the urinary bladder. Report of 2 cases with ultrastructural and immunohistochemical analyses. Eur Urol 1989, 16:237-239.

66. Liu SM, Wu JS: Pheochromocytoma of the urinary bladder-a case report Chin Med J 1988, 42:491-494.

67. Lenders JW, Sluiter HE, Rosenbusch G, Thien T: A pheochromocytoma of the urinary bladder. Eur J Radiol 1987, 7:274-275.

68. Cariem AK, Green JA, Fraser AG, Smith LR: Phaeochromocytoma of the bladder. A case report. South African Med J 1987, 71:178-179. 
69. Sakashita S, Tanda K, Togashi M, et al: Paraganglioma of urinary bladder, visualization with 1311-MIBG scintigraphy. Urol Int 1987, 42:237-240.

70. Burton EM, Schellhammer PF, Weaver DL, Woolfitt RA: Paraganglioma of urinary bladder in a patient with neurofibromatosis. Urology 1986, 27:550-552.

71. Davaris P, Petraki K, Arvanitis D, Papacharalammpous N, Morakis A, Zorzos S: Urinary bladder paraganglioma (U.B.P.). Pathol Res Pract 1986, 181:101-106.

72. Malossini G, Lotto A, Pisa R, Petracco S, Bianchi G: Pheochromocytoma of the urinary bladder. Acta Urol Belg 1986, 54:84-91.

73. McCormick SR, Dodds PR, Kraus PA, Lowell DM: Nonepithelial neoplasms arising within vesical diverticula. Urology 1985, 25:405-408.

74. Jurascheck F, Egloff H, Buemi A, Laedlein-Greilsammer D: Paraganglioma of urinary bladder. Urology 1983, 22:659-663.

75. Miller JL, Immelman EJ, Roman TE, Mervis B: Phaeochromocytoma of the urinary bladder localized by selective venous sampling and computed tomography. Postgrad Med J 1983, 59:533-535.

76. Das S, Bulusu NV, Lowe P: Primary vesical pheochromocytoma. Urology 1983, 21:20-25.

77. Khan O, Williams G, Chisholm GD, Welbourn RB: Phaeochromocytomas of the bladder. J R Soc Med 1982, 75:17-20.

78. Ochi K, Yoshioka S, Morita M, Takeuchi M: Pheochromocytoma of bladder. Urology 1981, 17:228-230.

79. Khan O, Williams G: Micturition with headache: phaeochromocytoma of the bladder. Eur Urol 1981, 7:112-114.

80. Hamberger B, Arner S, Backman KA, et al: Pheochromocytoma of the bladder. A case report. Scand J Urol Nephrol 1981, 15:333-335.

81. Flanigan RC, Wittmann RP, Huhn RG, Davis CJ: Malignant pheochromocytoma of urinary bladder. Urology 1980, 16:386-388.

82. Das S, Lowe P: Malignant pheochromocytoma of the bladder. J Urol 1980, 123:282-284.

83. Hanji AM, Rohan VS, Patel JJ, Tankshali RA: Pheochromocytoma of the urinary bladder: a rare cause of severe hypertension. Saudi J Kidney Dis Transpl 2012, 23(4):813-816.

84. Deng JH, Li HZ, Zhang YS, Liu GH: Functional paragangliomas of the urinary bladder: a report of 9 cases. Chin J Cancer 2010, 29(8):729-734. PubMed PMID: 20663319

85. Zeitlin I, Dessau H, Lorberboym M, Beigel Y: Malignant pheochromocytoma of the urinary bladder: challenges in diagnosis and management. Israel Med Assoc J 2011, 13:311-313.

86. National Cancer Institute at the National Institute of Health. http://www. cancer.gov/cancertopics/pdq/treatment/pheochromocytoma/ HealthProfessional/page2. Accessed 2/27/2012.

87. Averbuch SD, Steakley CS, Young RC, et al: Malignant pheochromocytoma: effective treatment with a combination of cyclophosphamide, vincristine, and dacarbazine. Ann Intern Med 1988, 109(4):267-273,

88. Gonias S, Goldsby R, Matthay KK, et al: Phase II study of high-dose [1311] metaiodobenzylguanidine therapy for patients with metastatic pheochromocytoma and paraganglioma. J Clin Oncol: official journal of the American Society of Clinical Oncology 2009, 27(25):4162-4168.

89. Dahm P, Gschwend JE: Malignant non-urothelial neoplasms of the urinary bladder: a review. Eur Urol 2003, 44:672-681.

doi:10.1186/1471-2490-13-22

Cite this article as: Beilan et al:: Pheochromocytoma of the urinary bladder: a systematic review of the contemporary literature. $B M C$ Urology 2013 13:22.

\section{Submit your next manuscript to BioMed Central and take full advantage of:}

- Convenient online submission

- Thorough peer review

- No space constraints or color figure charges

- Immediate publication on acceptance

- Inclusion in PubMed, CAS, Scopus and Google Scholar

- Research which is freely available for redistribution

Submit your manuscript at www.biomedcentral.com/submit
C Biomed Central 